University of Nebraska - Lincoln

DigitalCommons@University of Nebraska - Lincoln

2012

\title{
Reducing Courts' Failure-to-Appear Rate by Written Reminders
}

\author{
Brian H. Bornstein \\ University of Nebraska - Lincoln, bbornstein2@unl.edu
}

Alan J. Tomkins

University of Nebraska, atomkins@nebraska.edu

Elizabeth M. Neeley

University of Nebraska - Lincoln, eneeley2@unl.edu

Mitchel N. Herian

University of Nebraska - Lincoln, mherian2@unl.edu

Joseph A. Hamm

University of Nebraska - Lincoln, jhamm2@unl.edu

Follow this and additional works at: https://digitalcommons.unl.edu/publicpolicytomkins

Part of the Criminology Commons, Criminology and Criminal Justice Commons, Other Social and Behavioral Sciences Commons, Public Policy Commons, and the Social Control, Law, Crime, and Deviance Commons

Bornstein, Brian H.; Tomkins, Alan J.; Neeley, Elizabeth M.; Herian, Mitchel N.; and Hamm, Joseph A., "Reducing Courts' Failure-to-Appear Rate by Written Reminders" (2012). Alan Tomkins Publications. 19. https://digitalcommons.unl.edu/publicpolicytomkins/19

This Article is brought to you for free and open access by the Public Policy Center, University of Nebraska at DigitalCommons@University of Nebraska - Lincoln. It has been accepted for inclusion in Alan Tomkins Publications by an authorized administrator of DigitalCommons@University of Nebraska - Lincoln. 
Published in Psychology, Public Policy and Law (2012). DOI: 10.1037/a0026293. Copyright 2012, American Psychological Association. Used by permission. This is not the copy of record.

\section{Reducing Courts' Failure-to-Appear Rate by Written Reminders}

Brian H. Bornstein, Alan J. Tomkins, Elizabeth M. Neeley, Mitchel N. Herian, and Joseph A. Hamm

University of Nebraska-Lincoln

This article examines the effectiveness of using different kinds of written reminders to reduce misdemeanor defendants' failure-to-appear (FTA) rates. A subset of defendants was surveyed after their scheduled court date to assess their perceptions of procedural justice and trust and confidence in the courts. Reminders reduced FTA overall, and more substantive reminders (e.g., with information on the negative consequences of FTA) were more effective than a simple reminder. FTA varied depending on several offense and offender characteristics, such as geographic location (urban vs. rural), type of offense, and number of offenses. The reminders were somewhat more effective for Whites and Hispanics than for Blacks. Defendants with higher institutional confidence and those who felt they had been treated more fairly by the criminal justice system were more likely to appear, though the effectiveness of the reminder was greatest among misdemeanants with low levels of trust in the courts. The implications for public policy and pretrial services are discussed.

Keywords: Public trust and confidence, Procedural justice, Criminal justice, Field experiment

For the law to be effective, people must obey it (Caldeira, 1986; Tyler, 2006b). Although the law frequently involves elements of coercion, in practical terms the legal system has, at best, a limited ability to compel people to obey the law (e.g., Rottman, 2007; Tyler, 2006b). Voluntary acceptance minimizes the need for authorities to explain and justify each decision, reduces the need to monitor imple-

Brian H. Bornstein and Joseph A. Hamm, Department of Psychology and Public Policy Center, University of Nebraska; Alan J. Tomkins and Mitchel N. Herian, Public Policy Center, University of Nebraska; Elizabeth M. Neeley, Nebraska Bar Association and Public Policy Center, University of Nebraska-Lincoln.

This work was supported by a grant from the National Institute of Justice (Grant 2008-IJ-CX- 0022). Portions of this paper were presented at the 2010 meetings of the American Psychology-Law Society, American Society of Criminology, and American Judges Association.

We are grateful for the research assistance of Caitlin Cedfeldt, Lindsay Klug, Sucharitha Rajendran, Nicole Hutsell, Jennifer Li, and Maria Warhol, and for the contributions of Lisa PytlikZillig. We thank Linda Truitt, National Institute of Justice, for her support throughout the project; and staff at the Administrative Office of the Nebraska Courts, particularly Sherri Dennis and Ross Johnson, for help collecting data and for their insights. Furthermore, we thank the clerk magistrates from each of the 14 participating counties in Nebraska for allowing us to test this program.

Correspondence concerning this article should be addressed to Brian H. Bornstein, University of Nebraska-Lincoln, Lincoln, Nebraska, USA; bbornstein2@unl.edu. 
mentation, and limits the expenditure of scarce resources to ensure compliance (e.g., Robinson \& Darley, 1997; Tyler, 2006a).

One area of the criminal justice system where compliance is particularly lacking is in individuals' response to orders to appear in court for relatively minor offenses such as traffic offenses, misdemeanors, and low-level felonies. Noncustodial criminal defendants often fail to appear for court. This occurs for all kinds of mandated appearances: arraignment, pretrial (postarraignment) hearings, trial, and posttrial. Initial (i.e., arraignment) failure-to-appear (FTA) rates are particularly problematic, because they involve the greatest volume of defendants, most of whom are not detained prior to trial (Goldkamp \& White, 2006; VanNostrand \& Keebler, 2009). There are a number of alternatives to pretrial detention (VanNostrand \& Keebler, 2009), the most common of which, for minor offenses, is simply to release individuals in the community with little or no government oversight, placing the burden to appear in court entirely on defendants themselves (Goldkamp \& White, 2006). Not surprisingly, this can result in substantial FTA rates. FTA rates vary depending on jurisdiction and offense type, ranging from less than $10 \%$ (e.g., Cuvelier \& Potts, 1997; VanNostrand \& Keebler, 2009) to as high as 25-30\% (e.g., Davis, 2005; Helland \& Tabarrok, 2004; McGinty, 2000). These failures to appear are costly for both the court system and defendants (Levin, Kennel, Pellegrino, Simmons, \& Surett, 2007; Rosenbaum, Hutsell, Tomkins, Bornstein, Herian, \& Neeley, in press). For example, defendants can incur an additional charge for failing to appear, heightened penalties for the instant offense, issuance of an arrest warrant, and difficulty in obtaining bail.

Rates for failing to appear are comparatively high for minority defendants compared to Whites (O'Keefe, 2007; White, 2006). A possible explanation for this difference is that minorities have been found to have lower levels of trust and confidence in the courts (e.g., National Center for State Courts, 1999; Rottman, Hansen, Mott, \& Grimes, 2003; Rottman \& Tomkins, 1999), but little work has examined whether these racial and ethnic differences might also be associated with FTA. The present study explores the relationship among race and ethnicity, trust and confidence in the courts, and FTA.

\section{Using Reminders to Reduce FTA: An Expectancy Theory Approach}

Following the example set by the medical profession (e.g., Larson, Bergman, Heidrich, Alvin, \& Schneeweiss, 1982), several courts have effectively implemented court reminder programs designed to reduce FTA rates (Crozier, 2000; O'Keefe, 2007; White, 2006; see, generally, The Court Brothers, 2010a). For example, the Cook County (IL) Juvenile Court's postcard reminder program reduced the FTA rate from 38 to 13\% (Circuit Court of Cook County, 2006). Similarly, an evaluation of Coconino County (AZ) showed a reduction in the percentage of failures to appear at initial appearance in adult misdemeanor cases from over 25 to less than $13 \%$ when the defendant was called in advance and remind- 
ed of the hearing date (White, 2006). Reminder programs in Arapahoe County $(\mathrm{CO})$, Jefferson County (CO), and Multnomah County (OR) have also increased appearance rates and realized substantial labor and financial savings (Arapahoe County Justice Center, 2010; Jefferson County Criminal Justice Planning, 2005; O'Keefe, 2007), and they show some evidence of a disproportionate benefit for minorities (O'Keefe, 2007; White, 2006). The potential of reminder programs has even spawned a national reminder call business for courts (The Court Brothers, 2010b).

Although the results of reminder programs are promising, none to our knowledge has been guided by social scientific theory or research methodology to study the matter systematically - that is, comparing different types of reminders to determine which are more or less effective. To make the strongest contribution to both scientific theory building and policy development, psycholegal research should draw on relevant social scientific theories and research methods (Blumenthal, 2002; Wiener, 2007). The present study uses principles of expectancy theory (Vroom, 1964) to test the effectiveness of different kinds of written reminders. Prehearing reminders can be used to manipulate defendants' expectancies regarding the negative consequences of failing to appear, as well as the positive consequences of appearing. Both positive and negative expectancies can motivate choosing one behavioral option over another (Vroom, 1964) - here, whether or not to appear in court.

Although the expected outcomes of court proceedings are somewhat unpredictable and idiosyncratic to each case, the procedures themselves are relatively standardized. Individuals are more likely to accept adverse outcomes and follow unwanted directives when they perceive the procedures used to arrive at those outcomes as procedurally fair (e.g., Hegtvedt, Johnson, Ganem, Waldron, \& Brody, 2009; Thibaut \& Walker, 1975; Tyler, 2006a), and when they have high trust and confidence in governmental institutions (e.g., Baum, 2006; Gibson, Caldeira, \& Spence, 2003, 2005).

Perceptions of procedural justice have been examined in a range of contexts, both inside and outside the courtroom (e.g., Murphy, 2008; Tomkins \& Applequist, 2008; Tyler, 2007), and they have been studied in both experimental and more naturalistic settings (MacCoun, 2005). Studies looking at procedural justice and compliance typically vary (or assess) the level of procedural justice in some proceeding, and then measure its relationship to subsequent compliance (e.g., Barry \& Tyler, 2009; Murphy, 2008; Murphy \& Tyler, 2008). Other research focuses on individuals' expectancies of procedural justice, and measures its relationship to behavioral intentions or attitudes (e.g., Lind \& Tyler, 1988).

In some circumstances, such as court hearings, it is important to address individuals' expectancies early in the process, simply because an expectation of low procedural fairness or a failure to expect negative sanctions might lead them to avoid the court proceeding altogether (i.e., FTA). Thus, the present study seeks to manipulate criminal defendants' expectancies prior to attending their first court hearing. 


\section{Study Overview and Hypotheses}

Previous literature suggests that reminders would reduce defendants' FTA rate, and that reminders incorporating a substantive message - such as one designed to manipulate positive and/or negative expectancies - would be more effective than a simple reminder. The present study tests this hypothesis using a two-stage experiment. In Phase 1, defendants were randomly assigned to one of four reminder conditions: (a) a no-reminder or control condition; (b) a reminder-only condition; (c) a condition in which the reminder also makes them aware of negative consequences, in the form of possible sanctions, should they fail to appear (reminder-sanctions); and (d) a condition in which the reminder mentions sanctions but also highlights positive consequences, in the form of the procedural justice elements of voice, neutrality, respect, and public interest (reminder-combined). The primary dependent variable is whether defendants appear for their scheduled court date.

In Phase 2, we assessed a subset of participants' trust and confidence in the courts and perceptions of procedural justice using a survey administered after their scheduled appearance (or nonappearance). This allowed for an examination of the possible interaction between the reminder manipulation and participants' degree of trust and confidence.

For Phase 1, we predicted a linear effect of the reminder manipulation, such that individuals who received the reminder-combined postcard would be most likely to comply, followed by individuals who received the reminder-sanctions postcard, followed by participants in the reminder-only condition, who would be more likely to comply with court orders than those who received no reminder. We expected that the reminder-sanctions condition would be less effective than the reminder-combined condition, because some research shows that sanctions alone are not a very powerful means to get people to obey the law (Robinson \& Darley, 1997). Thus, sanctions - or the threat thereof-should be a less efficient means of influencing behavior than other tactics, especially expectancies based on a normative rationale (McAdams, 2000). However, one might also reason that members of the studied population - individuals charged with breaking the law - would be relatively suspicious about expectancies proffered by the court system, especially positive expectancies related to fair treatment. If so, then the remindercombined condition might be less effective than it would be with a nonoffending population.

We made two hypotheses related to race and ethnicity, based on prior research (e.g., O'Keefe, 2007). First, we predicted a higher FTA rate for minorities than for Whites; second, we predicted an interaction between the reminder manipulation and defendants' race and ethnicity, such that the reminders would be effective for minority defendants but not necessarily for White defendants.

For Phase 2, we hypothesized that trust and confidence in the judicial system and defendants' procedural justice assessments would be greater for defendants who appeared in court than for defendants who failed to appear. We also predicted lower trust and confidence for minorities than for Whites. Finally, we predicted an interaction between the reminder treatment and individuals' trust and con- 
fidence. Specifically, individuals with high levels of trust and confidence would have a high likelihood of complying with court orders, regardless of the treatment level that was administered (see, e.g., Scholz \& Lubell, 1998; Tyler, 2006b; Tyler \& Rasinski, 1991). The expectancy of sanctions and/or fair treatment, created by the reminder manipulation, would exert a stronger effect in individuals with relatively low trust and confidence in the courts.

Method

Participants

The sample for Phase 1 consisted of 7,865 misdemeanor defendants from 14 counties in Nebraska. Data collection began in March 2009 and continued through May 2010. The selected counties included both urban (e.g., Lincoln and Omaha) and rural portions of the state. All misdemeanants meeting certain eligibility criteria (e.g., age 19 years or older [the age of majority in Nebraska], type of offense, scheduling of court hearing) were included in the sample. For example, we excluded offenses for which defendants could waive their court appearance (appearance in court is not mandatory for waiverable offenses, which can be handled by the defendant via mail). This included the majority of minor traffic offenses (e.g., suspended license, no proof of insurance) and offenses such as disturbing the peace, disorderly conduct, open container, and so on. We also excluded cases that were entered into the state court's computer system too close to the assigned court date, because it limited our ability to send a timely reminder. The sample was racially diverse: $69.8 \%$ White, 10.7\% Hispanic; 10.1\% Black, 6.6\% Unknown; 1.6\% Native American; $1 \%$ Asian American; and .2\% Other (racial classifications were made by the officer issuing the citation).

All of the misdemeanor categories provided for by state statute were represented in the sample, with most coming from the relatively severe categories. For example, 30.5\% of defendants were charged with an alcohol-related misdemeanor (e.g., first offense driving-under-the-influence charge) and an additional 31.0\% were charged with violations of city ordinances (e.g., injuring or destroying property). Roughly one sixth (17.6\%) were charged with a Class 1 misdemeanor (e.g., carrying a concealed weapon, first offense; failing to stop and render aid), with the remainder charged with a Class 2 (9.3\%; e.g., shoplifting \$0\$200) or Class 3 misdemeanor (11.2\%; e.g., minor in possession of alcohol). Four individuals were charged with a Class $3 \mathrm{~A}$ misdemeanor $(0.1 \%$; e.g., possession of marijuana, third offense); 21 were charged with a Class 4 misdemeanor (0.3\%; e.g., possession of marijuana, second offense); and five were charged with a Class 5 misdemeanor $(0.1 \%$; e.g., unlawful entry of state park without a park permit). For analytical purposes, we combined the latter three categories with Class 3 misdemeanors.

A subset of the Phase 1 misdemeanants comprised the Phase 2 sample. Specifically, all of the misdemeanants who did not appear for their hearing and 20\% (randomly selected) of those who appeared were sent a survey prenotification one 

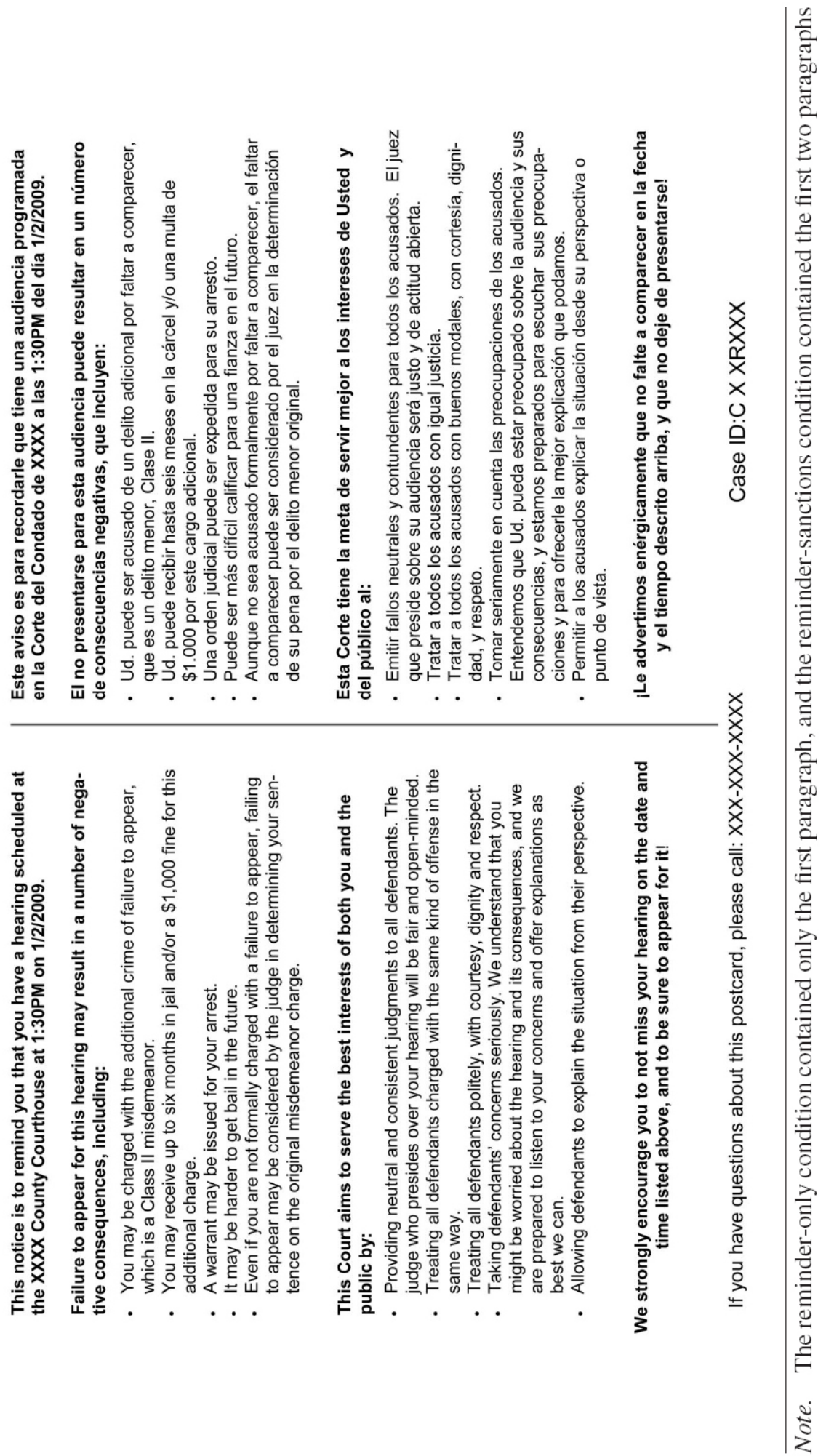
week after their scheduled court hearings alerting them to a forthcoming survey (i.e., we followed Dillman's [2007] recommended procedures). Two weeks after the scheduled hearing dates, participants were mailed the actual survey with a $\$ 2$ bill as an incentive. Replacement surveys were mailed two weeks later if they had not already been returned. Surveys were sent to 2,357 individuals $-1,538$ to those who appeared for their court dates and 819 who did not appear. We received surveys from 335 defendants who appeared in court and from 117 who failed to appear ( $\mathrm{N} 452)$. The response rate was $21.6 \%$ for participants who appeared in court and $14.5 \%$ for those who failed to appear, making the overall response rate $19.2 \%$. The demographics of the Phase 2 sample were fairly comparable to the Phase 1 sample, although Whites comprised a slightly larger proportion of Phase 2 respondents (77.6\%), and Blacks and Hispanics comprised slightly smaller proportions than in the Phase 1 sample $(7.8 \%$ and $5.7 \%$, respectively).

Materials, Design, and Procedure

Phase 1. Each defendant in the participating counties was randomly assigned to one of four conditions (see Table 1): (a) no-reminder or control, (b) reminder-only, (c) reminder-sanctions, or (d) reminder-combined. The reminder-only condition consisted of a message printed on a postcard reminding the defendant that he or she was scheduled to appear in court on a specified date and time. The reminder-sanctions condition contained this information as well as an explanation of the negative consequences of failing to appear. The message in the reminder-combined condition contained the same information as the reminder-sanctions condition and it also emphasized the various conceptual components of procedural justice (voice, dignity, respect, and public interest) that were attendant to the defendant's appearance in court.

We did not include a positive-consequences-only condition, with no mention of sanctions, because feedback from court personnel suggested that it would be unrealistic for courts to include the "positive" information without also mentioning the "negative" (it would also be potentially unethical, because a positive-only condition might imply an absence of penalties for FTA). The reminders were in a bilingual format (English and Spanish, reverse translated for accuracy) and sent by postal mail several days before defendants' scheduled court appearances. If any mailings were returned because of an incorrect address, the individual was immediately removed from the sample.

The messages in the respective conditions were pretested on a separate sample, to ensure that the manipulations captured the constructs of interest. Pretest participants $(n=55)$ were recruited from the University of Nebraska- Lincoln psychology department online study website (http:/ / www.experimetrix.com) and were offered extra credit for completing the survey. Participants were asked to imagine that they had been cited for a misdemeanor and had a court date scheduled, and then they completed a questionnaire asking several questions about their ex- 
pectations regarding the fairness of the procedure (e.g., "How likely do you believe it is that the court [i.e., the judge] would listen to your opinions?" "How likely do you believe it is that you would be treated in court with dignity and respect?"). They were then told to imagine that they had received a reminder prior to their court dates (using the language from the reminder-only condition), and answered the same questions. Then they saw either the reminder-sanctions postcard or a reminder describing just the benefits of appearing, followed by the reminder-combined condition (with either the negative or the positive information presented first, counterbalanced across participants; as described above, we ultimately dropped the "positive-only" condition). Thus, they answered the same questions for each of four conditions. The reminder-combined condition (with the negative sanctions presented first) was perceived as significantly fairer than both the control condition, $t(28)=3.35, p=.002, d=.55$, and the reminder-only condition, $t(28)=2.65, p=.013, d=.49$. In contrast, the reminder-sanctions condition was rated as no fairer than either the control or the reminder-only condition, $t(26)$ $\mathrm{s}<1, p s>.50$. These results provided the language for the postcard manipulation in the main study.

Phase 2. The survey asked participants to rate how much various factors affected their decision to appear (or not to appear) in court on 5-point scales, ranging from 1 (not at all) to 5 (very much). They also responded to items assessing confidence in the courts (e.g., "Judges in my county do their jobs well"), cynicism (e.g., "People in power use the law to control people like me"), general trust in governmental institutions (e.g., "How often can you trust the U.S. government to do what is right?"), obligation to obey the courts (e.g., "I feel I should accept the decisions of legal authorities"), and dispositional trust (e.g., "Generally speaking, do you think most people can be trusted?"). These constructs measure discrete aspects of trust and confidence (Hamm et al., 2011). Responses were made on 5-point scales ranging from 1 (not at all) to 5 (very much) or from 1 (strongly disagree) to 5 (strongly agree).

We also asked three questions of all participants relevant to procedural justice (referred to henceforth as general-PJ), inquiring about their assessments with the judicial system in general regarding its fairness, bias, and the respect with which they were treated from the time of their ticket to the time they completed the survey, whether or not they appeared in court (but excluding their experience with law enforcement personnel, such as the officer who issued the ticket). For those who appeared for their hearings, we also asked more extensively about their procedural justice perceptions regarding their court appearances, using an eightquestion scale targeting the subconstructs of fairness, voice, dignity, and respect (referred to henceforth as specific-PJ). Responses were made on 5-point scales, ranging from 1 (very unfair) to 5 (very fair) or from 1 (very respectfully) to 5 (very disrespectfully). Finally, we collected demographic data from each participant. 
Table 2

Failure to Appear Rate by Experimental Condition

Reminder postcard treatment Control Reminder-only Reminder-sanctions Reminder-PJ Total

\begin{tabular}{rcc}
\multicolumn{2}{c}{ Appeared for court } & \\
No & Yes & Total \\
$12.6 \%$ & $87.4 \%$ & 2095 \\
$10.9 \%$ & $89.1 \%$ & 1889 \\
$8.3 \%$ & $91.7 \%$ & 1901 \\
$9.8 \%$ & $90.2 \%$ & 1980 \\
$10.4 \%$ & $89.6 \%$ & 7865
\end{tabular}

\section{Results}

Phase 1

FTA rate and case disposition. The baseline (control) FTA rate was $12.6 \%$; it was $10.4 \%$ across all conditions. For defendants who appeared in court, there were a number of possible case dispositions. For all defendants, $78.8 \%$ pleaded guilty in court, while the charge was dismissed in $11.6 \%$ of cases. An additional $6.2 \%$ pleaded guilty by waiver. ${ }^{1}$ Only $3.4 \%$ of cases went to trial; of these, nearly all were bench trials.

FTA across conditions. The FTA rate varied significantly across conditions (see Table 2), $\chi^{2}(3)=20.90, p<.001, \Phi=.05$. Post hoc contrasts showed a difference between receiving any reminder $(9.7 \%$ FTA rate) versus the noreminder control condition, $\chi^{2}(1)=14.29, p<.001, \Phi=.04$. There was also a significant difference between the simple reminder and the two conditions with more substantive information (i.e., reminder-sanctions and reminder-combined), $\chi^{2}(1)=4.63, p=.031, \Phi$ $=.03$. The FTA rate was slightly higher in the reminder-combined condition than in the reminder-sanction condition, but this difference was not statistically significant, $\chi^{2}(1)=2.60, p=.11, \Phi=.03$.

Table 3

Regression Results: Factors Associated With Failure to Appear

Variable

Reminder treatment

Race

Reminder treatment by race

Gender

Urban/rural

Offense type

Number of offenses

Constant

Note. Cox \& Snell $\mathrm{R}^{2}=.044$.

${ }^{*} \mathrm{p}=.085 .{ }^{* *} \mathrm{p}<.001$.

$\begin{array}{cr}\beta(S E) & \text { Wald } \\ .14^{*}(.08) & 2.96 \\ -.09(.09) & 1.00 \\ -.01(.05) & .06 \\ -.10(.09) & 1.13 \\ .41^{* *}(.11) & 13.44 \\ -.18^{* *}(.03) & 42.71 \\ -1.28^{* *}(.10) & 172.86 \\ 4.48(.34) & 177.47\end{array}$

2.96

1.00

1.13

13.44

172.86

177.47

$\begin{array}{rc}\operatorname{Exp}(b) & 95 \% \mathrm{CI} \\ 1.14 & {[0.98,1.34]} \\ .91 & {[0.77,1.09]} \\ .99 & {[0.90,1.09]} \\ .91 & {[0.76,1.08]} \\ 1.50 & {[1.21,1.86]} \\ .83 & {[0.79,0.88]} \\ .28 & {[0.23,0.34]} \\ 87.90 & \end{array}$

\footnotetext{
${ }^{1}$ We were unable to obtain disposition data on approximately $16 \%$ of the cases. Also, as noted above, all waiverable offenses and traffic cases were removed from our sample before reminder postcards were mailed to defendants, which raises the question of how cases in the sample could be disposed of by waiver. Most of the cases disposed through a waiver were originally nonwaiverable cases that were amended by the courts. Finally, a number of waiverable cases at the city level appear to have been inadvertently included in the sample because our screening criteria were based on state statutes rather than city ordinances.
} 
Table 4

Failure to Appear Rate by Offense Type

\begin{tabular}{|c|c|c|c|c|c|c|c|c|c|c|}
\hline \multirow[b]{2}{*}{ Offense type } & \multicolumn{2}{|c|}{$\begin{array}{l}\text { All } \\
\text { conditions } \\
\text { FTA }\end{array}$} & \multicolumn{2}{|c|}{$\begin{array}{l}\text { Control } \\
\text { FTA }\end{array}$} & \multicolumn{2}{|c|}{$\begin{array}{l}\text { Reminder } \\
\text { only } \\
\text { FTA }\end{array}$} & \multicolumn{2}{|c|}{$\begin{array}{l}\text { Reminder } \\
\text { sanctions } \\
\text { FTA }\end{array}$} & \multicolumn{2}{|c|}{$\begin{array}{l}\text { Reminder } \\
\text { combined } \\
\text { FTA }\end{array}$} \\
\hline & rate & $n$ & rate & $n$ & rate & $n$ & rate & $n$ & rate & $n$ \\
\hline Class 1 & 7.6 & 1377 & 7.3 & 358 & 8.2 & 365 & 7.0 & 330 & 8.0 & 324 \\
\hline Class W (alcohol) & 9.4 & 2389 & 9.7 & 628 & 11.1 & 96 & 7.2 & 567 & 9.4 & 598 \\
\hline Class 2 & 13.8 & 732 & 18.9 & 212 & 11.7 & 145 & 10.5 & 191 & 13.0 & 184 \\
\hline Class 3/3A/4/5 & 8.4 & 908 & 10.2 & 254 & 8.5 & 213 & 6.8 & 220 & 7.7 & 2212 \\
\hline City ordinance & 12.9 & 2424 & 17.5 & 636 & 13.2 & 560 & 10.1 & 587 & 10.6 & 641 \\
\hline
\end{tabular}

Note. FTA rates are percentages. The Method section gives examples of each offense type.

Factors associated with FTA. Secondary analyses focused on differences in FTA rate as a function of several factors, specifically (a) defendants' race and ethnicity, (b) defendant sex, (c) geographic location (specifically, rural vs. urban counties), (d) offense type, and (e) number of charges. To explore these relationships, we estimated a logistic regression model with all of these factors as predictors of the overall FTA rate as well as reminder condition. The model also included the predicted interaction between reminder and race/ethnicity (see Table 3).

Controlling for these other factors, the effect of the reminder manipulation was reduced, but was still marginally significant, $\beta=.14, p=.085$. This suggests that the reminders were still effective, but that FTA was also associated with some of the other factors included in the regression model, as discussed next. We predicted that minorities would have higher FTA rates than Whites. The overall FTA (all conditions combined) rate varied as a function of defendant race and ethnicity: White $(9.5 \%)$ versus Black $(16.4 \%)$ versus Hispanic $(9.4 \%)$. However, when controlling for sex, location, offense type, and number of charges, the effect of race and ethnicity was not significant, $\beta=-.09, p=.32$.

The FTA rate also did not differ significantly as a function of defendant sex: Male $(10.8 \%)$ versus Female $(9.4 \%), \beta=-.10, p=.29$. The FTA rate varied across geographic locations and was higher in urban $(12.4 \%)$ than rural counties $(6.8 \%), \beta=$ $.40, p<.001$. We also examined whether FTA rates differed by the type of offense and by the number of charges issued for each court hearing. FTA rates differed significantly as a function of the type of offense (see Table 4 ), $\beta=-.18, p<.001$. Individuals charged with Misdemeanor 2 offenses and violations of city ordinances were the most likely to FTA.

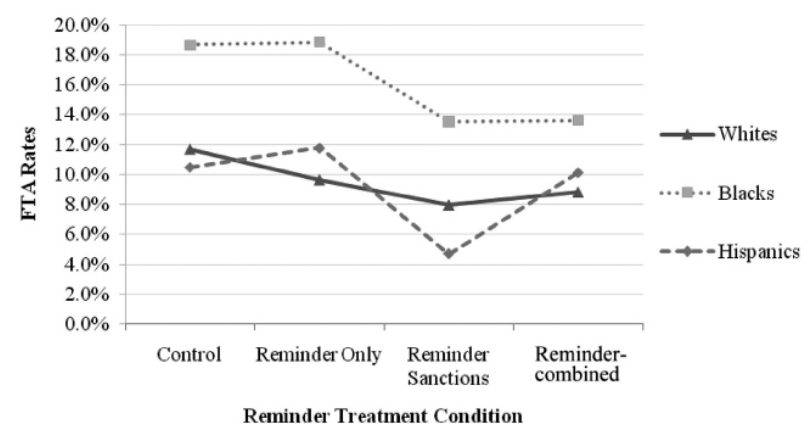

Figure 1. FTA rates by race and reminder condition. 
FTA rates also differed significantly depending on the number of charges issued on each ticket (coded as 1 vs. 2 or more), with the likelihood of FTA increasing with the number of citations on the ticket, $\beta=-1.28, p<.001$. Only $5.4 \%$ of individuals with one offense failed to appear, whereas $15.4 \%$ of individuals with two or more offenses did not appear. Based on the results of this analysis, and in relation to the other analyses conducted above, it appears that number of offenses is one of the strongest predictors of FTA.

Differential effectiveness of reminders by race and ethnicity. We predicted that the postcard reminders would be effective for minorities but not for Whites (i.e., a race by reminder interaction). The interaction between race and reminder was nonsignificant, $\beta=-.01, p=.80$. Thus, the effectiveness of the reminders was essentially comparable for the three major racial groups (see Figure 1). However, because we predicted an effect for minorities but not for Whites, we examined treatment effects for each racial and ethnic group separately.

For Whites, the FTA rate ranged from 11.7 to $8 \%$, depending on the treatment, a finding that was significant, $\chi^{2}(3)=12.26, p=.007, \Phi=.05$. Follow-up tests comparing each reminder condition to the control condition showed that the reminder-sanctions condition was effective, $\chi^{2}(1)=10.78, p=.001, .06$, as was the reminder-combined condition, $\mathrm{X}^{2}(1)=6.21, p=.013, \Phi=.05$; however, the reminder-only condition did not greatly reduce FTA among Whites, $\chi^{2}(1)=2.94, p=.086, \Phi=.03$. For Blacks, the various treatments did not appear to have the same effect. The FTA rate for Blacks ranged from $18.7 \%$ in the control condition to $13.5 \%$ in the reminder-sanctions condition, but the omnibus test was not significant, $\chi^{2}(3)=3.85$, $p=.28, \Phi=.07$. For Hispanics, there was a marginally significant difference in FTA rate across the conditions, $\chi^{2}(3)=6.81, p=.078, \Phi=.09$.

As with Whites, the reminder with sanctions had the greatest absolute impact on reducing FTA rates, given that the FTA rate was reduced to 4.7 from $10.5 \%$ in the control condition, $X^{2}(1)=4.94, p=.026, \Phi=.11$. The other reminders did not significantly reduce FTA below the baseline level among Hispanics, $\chi^{2}(1) s<2$, ps $>.5$.

\section{Phase 2}

In a previous study, we found that our trust and confidence items could be statistically and conceptually organized into four distinct subscales (Hamm et al., 2011): Trust in the Courts, Cynicism, General Trust in Institutions, and Obligation to Obey. Here we present data from the Trust in the Courts subscale $(\alpha=.85)$, as well as a Total Institutional Confidence measure (combining all four subscales; $a$ $=.77$ ), because those are most relevant to the present study. Because the construct of Dispositional Trust is conceptually different from a person's perceptions about institutions (i.e., it looks at people's general trust of others), we examined this construct separately $(\alpha=.78)$.

We also measured defendants' perceptions of procedural justice. We asked all defendants three general questions about courts' fairness, bias, and respect related to the judicial system in general (general-PJ). We also asked the defendants who ap- 
peared for their hearings $(n=251)$ eight questions about their case-specific procedural justice perceptions (specific-PJ). Alpha levels for both PJ scales were fairly high (.92 and .82, respectively). There was a strong relationship between the two sets of questions, each treated as a scale, $r(324)=.66, p<.01$.

Trust and confidence, PJ, and FTA. We hypothesized that those defendants who appeared for their hearings would indicate greater levels of trust and confidence and have greater levels of perceived procedural justice than those who did not appear. Defendants who appeared in court for their hearing had significantly greater Total Institutional Confidence scores $(M=3.24)$ than those who did not appear $(M=3.02), F(1,445)=7.82, p=.005,{ }^{\eta_{p}^{2}}=.02$, as well as greater Trust in the Courts scores $(M=3.30$ for appearers; $M=3.04$ for nonappearers), $F(1,441)=7.78, p=$ $.006, \mathrm{\eta}_{\mathrm{p}}^{2}=.02$. Additionally, there was a relationship between perceptions of (general) procedural justice and appearance, $F(1,438)=6.61, p=.01$, $\eta_{p}^{2}=.02$, such that those who appeared for their hearings perceived greater levels of procedural justice in their overall experience with the criminal justice system $(M=3.53 \mathrm{vs} . M=$ 3.23).

We also discovered strong relationships between the various constructs of interest. For example, the correlation between Total Institutional Confidence and general-PJ was significant $r(440)=.59, p<.001$, as was the correlation between Trust in the Courts and general-PJ, $r(438)=.65, p<.001$. Furthermore, among those who appeared for court, there were strong relationships between Total Institutional Confidence and specific-PJ, $r(324)=.57, p<.001$, and between Trust in the Courts and specific-PJ, $r(323)=.64, p<.001$.

We next examined the potential relationships between the reminder manipulation and perceptions of general and specific procedural justice. The results showed no effect in either case, $F(3,436)=1.15, p=.33,{ }^{\eta_{p}^{2}}=.01$, and $F(3,320)=.44, p=.72$, $\eta_{p}^{2}=.00$, respectively.

We hypothesized that there would be a race and ethnicity effect, with Whites having greater trust and confidence than minorities. Comparing Whites, Blacks, and Hispanics, there were significant differences on a number of constructs related to trust (see Table 5). Whites had greater dispositional trust than both Blacks and Hispanics, $F(2,401)=9.20, p<.001, \mathrm{\eta}_{\mathrm{p}}^{2}=.04$. Notably, we also found that there was a significant difference across the three racial and ethnic categories on Total

Table 5

Trust and Confidence and Procedural Justice Scale Means by Race and Ethnicity

\begin{tabular}{lcccccccc}
\multicolumn{7}{c}{ Whites } & \multicolumn{2}{c}{ Blacks } \\
Scale & Mean & SD & Mean & SD & Mean & SD & F & $p$ \\
Trust in the Courts & $3.26^{\mathrm{a}}$ & 0.84 & $2.79^{\mathrm{b}}$ & 0.91 & $3.24^{\mathrm{a}, \mathrm{b}}$ & 0.87 & 4.34 & .014 \\
Total Institutional Confidence & $3.20^{\mathrm{a}}$ & 0.70 & $2.84^{\mathrm{b}}$ & 0.81 & $3.15^{\mathrm{a}} \mathrm{b}$ & 0.66 & 3.71 & .025 \\
Dispositional Trust & $2.90^{\mathrm{a}}$ & 0.80 & $2.34^{\mathrm{b}}$ & 1.02 & $2.44^{\mathrm{b}}$ & 0.89 & 9.20 & .000 \\
General Procedural Justice & 3.35 & 1.04 & 3.13 & 1.31 & 2.99 & 0.98 & 0.23 & .795 \\
Specific Procedural Justice & 3.47 & 1.04 & 3.38 & 1.13 & 3.35 & 1.03 & 1.34 & .264
\end{tabular}

Note. Within a row, means with different superscripts $-\mathrm{a}$ and $\mathrm{b}$-differ significantly, $p<.05$. 


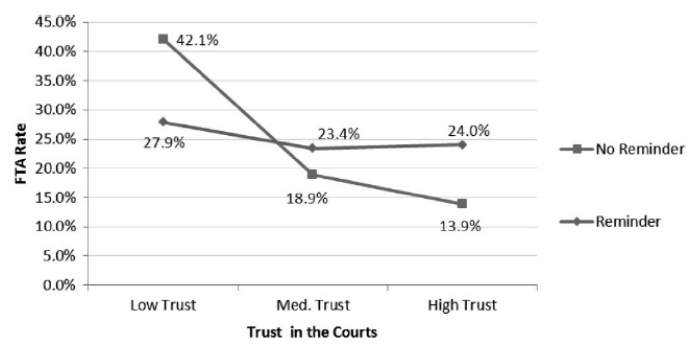

Figure 2. FTA rates as a function of trust in the courts and reminder treatment.

Institutional Confidence, $F(2,402) 3.71, p=.025,{ }^{\eta_{p}^{2}}=.02$, and Trust in the Courts, $F(2,398)=4.34, p=.014, \mathrm{\eta}_{p}^{2}=.02$. Post hoc tests showed that on both variables, the significant difference was driven largely by the gap between Whites and Blacks rather than any differences between Whites and Hispanics, or between Blacks and Hispanics. Together, the findings suggest that although Blacks differed from Whites on all measures of trust and confidence, Hispanics were closer to Blacks on some measures, but closer to Whites on others.

Finally, we hypothesized that the level of trust and confidence would interact with the reminder manipulation, such that the reminder would be more effective for defendants relatively low in trust. We conducted a binary logistic regression to examine this hypothesis, with appearance as the dependent variable. Because the Phase 1 analyses showed that the largest effect was for receiving any reminder versus the control condition, we dichotomized the reminder variable (i.e., any reminder vs. none); trust in the courts was categorized as low, medium, or high; and we controlled for participants' race using dummy variables.

The results (see Figure 2) revealed that, consistent with the results reported above, higher levels of trust in the courts were associated with a greater probability of appearing, $\beta=0.79, p=.008, \operatorname{Exp}(b) 2.21, \operatorname{Exp}(b) C I[1.23,3.94]$. As in the Phase 1

Table 6

Reasons for Appearance or Nonappearance

Reason

Mean SD

Reason for appearance

I wanted to avoid an additional offense (for failure to appear) on

my record.

I wanted to avoid additional penalties.

I felt I should obey the law.

The system depends on compliance from people like me.

I wanted to tell my side of the story.

Reason for nonappearance

I had scheduling conflicts.

I had work conflicts.

I had transportation difficulty.

I forgot about the hearing date.

I had family conflicts (e.g., childcare conflicts).

I was afraid of what the outcome would be if I went to court.

$4.60 \quad 1.02$

$4.59 \quad .98$
4.38

$\begin{array}{ll}4.38 & 1.05\end{array}$

$3.73 \quad 1.37$

$3.16 \quad 1.62$

$2.77 \quad 1.81$

$2.39 \quad 1.66$

$\begin{array}{ll}2.07 & 1.59\end{array}$

$1.89 \quad 1.50$

$1.84 \quad 1.44$

$1.72 \quad 1.20$

Note. The scale ranged from 1 (affected not at all) to 5 (affected very much). Ns ranged from 317-325 for appearers and from 109-113 for nonappearers. 
analysis of the full sample, there was also an effect of the reminder manipulation, such that the FTA rate was lower for those who received a reminder than for those who did not, $\beta=1.32, p=.045, \operatorname{Exp}(b)=3.73, \operatorname{Exp}(b) C I[1.03,13.51]$. Supporting our hypothesis, there was also a significant interaction, $\beta=-.70, p=.039, \operatorname{Exp}(\mathrm{b})=.50$, $\operatorname{Exp}(b) C I[.26, .97]$. As Figure 2 shows, the reminder marginally reduced FTA for those with low trust in the courts $(p=.05$, one-tailed), but it did not affect FTA for those with medium $(p=.28)$ or high $(p=.10)$ trust. Put another way, the reminder eliminated differences in FTA as a function of degree of trust in the courts.

Reasons for (non)appearance. We also examined why defendants did or did not appear for their court appearance (see Table 6). The factors that participants judged most important in their deciding to appear for court were wanting to avoid additional offenses for FTA or additional penalties, or feeling they should obey the law. In contrast, defendants who did not appear rated scheduling conflicts as having the greatest effect on their decision. Notably, nonappearers did not seem to view forgetting their hearing date, family conflicts, or fear of the outcome as major reasons for their nonappearance.

\section{Discussion}

The Phase 1 findings replicate previous research in showing that a reminder effectively reduces the FTA rate. A more substantial reminder, containing information about possible sanctions for FTA, was more beneficial than a simple reminder, suggesting that the expectation of negative consequences modified defendants' behavior (Vroom, 1964). However, inclusion of a more positive expectancy message, derived from procedural justice principles, did not yield additional benefit. Indeed, there was some indication that the reminder with only negative, threatening information (i.e., the reminder-sanctions condition) was the most effective method of reducing FTA rates for all three racial groups we examined (the sanctions condition reduced the FTA rate by 3.7\% for Whites, 5.2\% for Blacks, and 5.8\% for Hispanics; these reductions were statistically significant for Whites and Hispanics, but not for Blacks).

The effectiveness of the reminder with sanctions was surprising, inasmuch as research shows that sanctions alone are not a very powerful means to get people to obey the law (Robinson \& Darley, 1997). In addition to this finding, the analysis of participants' reasons for (non)appearance likewise showed a greater emphasis on instrumental than on normative concerns, especially among nonappearers. It is possible that the decision-making calculus is different in an offending population, and that the threat of sanctions in particular, and instrumental considerations generally, are particularly effective for this group - perhaps due to greater lifetime experience with clear behavioral contingencies, especially of a punitive nature, than with more abstract, normative reasoning.

FTA differed as a function of demographic and offense characteristics, especially geographic location (urban vs. rural), offense type, and number of charges. The difference between urban and rural communities likely reflects the greater sense 
of anomie and disconnectedness in urban centers, compared to more closely knit rural settings (Curry, 2000). The FTA rate did not differ across race and ethnicity when controlling for these other factors. Racial and ethnic minorities are quite diverse, and it is problematic to focus on race without consideration of variables that might covary along with race (e.g., Covington, 1995; Hitlin, Brown, \& Elder, 2007). Furthermore, the fact that $54.9 \%$ of the Hispanic sample came from rural areas might suggest that rural Hispanics are particularly aware of the sanctions associated with FTA. The data on offense type and number of charges suggest that FTA is more likely for more serious cases (i.e., more severe offenses, multiple charges; VanNostrand \& Keebler, 2009).

The most striking finding from Phase 2 was that trust and confidence correlated significantly with court appearances. This finding is consistent with other demonstrations that trust and confidence are an important construct for understanding compliance with the law generally (Murphy, 2008; Scholz \& Lubell, 1998). It is also relevant to understanding racial and ethnic differences in compliance (e.g., Brooks \& Jeon-Slaughter, 2001; Tyler, 2001). Minorities tend to have less trust in various authorities than Whites (e.g., the medical system as well as the legal system; see Corbie-Smith, Thomas, \& St. George, 2002). In our dataset, the race effect was not uniform: Blacks and Hispanics were similar in dispositional trust (and different from Whites), but Hispanics resembled Whites in their confidence in the courts and total institutional confidence. Hispanics were also similar to Whites in FTA, suggesting that situation-specific trust and confidence measures may be better predictors of racial and ethnic differences in compliance than more stable, dispositional measures. Other research has similarly found that Hispanics are intermediate between Whites and Blacks in their attitudes toward legal authorities, such as police (Weitzer \& Tuch, 2006).

We also found support for the expected interaction between the reminder manipulation and trust in the courts, with evidence that a reminder was most effective for defendants relatively low in trust. Indeed, the relationship between trust in the courts and (non)appearance disappeared when defendants received a reminder. Thus, reminders have the potential to equalize appearance rates for defendants who vary in their attitudes toward the criminal justice system.

\section{Limitations and Future Directions}

One limitation of this study is whether the message in the reminder-combined condition was sufficiently potent. Pretesting of the postcard manipulation indicated it was significantly different from the other postcard reminders. However, the pretesting was done with a college student sample. Compared to nonoffenders, actual defendants might have been more skeptical about the positive aspects of the message (i.e., voice, respect, etc.), particularly if they had had bad experiences with the criminal justice system in the past. Indeed, there was evidence of substantial cynicism in the Phase 2 sample, with those failing to appear being significantly more cynical than those who appeared. 
It is unclear how to overcome this limitation, as an even stronger message would likely be met with the same cynicism. It is possible that a telephone reminder from court personnel emphasizing positive expectancies could accomplish this goal, but it would be offset by the substantial additional investment of labor and time. Prerecorded telephone reminders are potentially more efficient, but any added benefit of a phone reminder might only accrue from a "live" individual who could provide a more personal touch and also answer questions. Future research should directly compare print versus phone reminders, taking into account the costs as well as the benefits of reduced FTA (Rosenbaum et al., in press).

One alternative solution is simply to accept that negative messages might be more effective at changing expectancies and inducing desirable behavior in this context than positive messages. For example, recent field experiments have shown that shame can work as a potentially powerful "commitment device" that motivates people to act prosocially, work toward long-term strategies, and engage in civic activities (deHooge, Breugelmans, \& Zeelenberg, 2008; Gerber, Green, \& Larimer, 2010). Perhaps lessons from such field experiments can inform future efforts to understand compliance with both civic duties and legal obligations.

In addition to these limitations to the reminder manipulation, there were limitations to the Phase 2 survey. For example, it did not include measures of perceived outcome favorability or outcome fairness, which are themselves important determinants of perceived procedural fairness (Bornstein \& Dietrich, 2007; Skitka, Winquist, \& Hutchinson, 2003). In measuring procedural fairness only after the court hearing-due to the close proximity of the scheduling process to the actual hearing dates - it was impossible to measure positive expectancies before the court date; this is an important limitation that should be addressed by future research. Nonetheless, a large majority (84.4\%) of participants correctly reported that they had received (and presumably read) a reminder postcard. This does not show whether the manipulation actually affected their expectancies, but in combination with the finding that the reminder information about negative consequences affected appearance rates, it does suggest that participants processed the manipulation as intended.

Future research should also extend the racial and ethnic findings of the present study. The sample contained too few Native Americans, despite being double the statewide percentage, as well as too few Asian Americans, to address FTA in these groups. Larger-scale research could target areas in states with large populations of Native Americans and Asian Americans. On the other hand, defendants from the rural counties in our sample contained a substantial number of Hispanics $(16.6 \%)$. This diversity provides valuable information about rural Hispanics in the United States, because there is a general lack of research on this population, which makes up an increasing proportion of rural populations across the United States (Kandel \& Cromartie, 2004).

Finally, future research should address the effectiveness of reminders at reducing FTA among felony defendants. Felony defendants are less likely than misdemeanor defendants to have the opportunity to FTA, because they are often in custody; 
nonetheless, many felony defendants awaiting trial are released on bond. On the one hand, they might be more likely to appear, because the penalty for FTA (e.g., forfeited bail) is potentially greater. On the other hand, they might be less likely to appear, because the prospect of a stiffer sentence if they are tried and convicted could give them greater incentive to flee. Our finding that defendants with more charges - and hence stiffer potential penalties - were less likely to appear suggests that this latter expectation is more likely.

Implications for Criminal Justice Policy and Practice

Despite these limitations, the study has important implications for criminal justice policy and practice, such as improving system efficiencies and cost savings through better compliance, improving criminal defendants' perceptions of the courts, and reducing racial and ethnic disparities in the criminal justice system. FTA rates vary widely across jurisdictions, but even lower-end estimates in the $10 \%$ range (e.g., VanNostrand \& Keebler, 2009) - which are consistent with the overall FTA rate in the present sample ( $12.6 \%$ in the control condition) - are costly for both defendants and the court system as a whole (Levin et al., 2007). Reducing FTA rates, by even a few percentage points, can have significant financial and labor savings (O'Keefe, 2007; Rosenbaum et al., in press). Another benefit of lower FTA rates might be additional revenue in the form of fines collected from defendants who do appear.

Knowing which types of misdemeanants are most likely to FTA-such as those in urban locales, with multiple charges, or cited for certain offenses - has implications for how to allocate pretrial services most efficiently. The present findings suggest that targeting defendants with multiple charges or in urban centers using a reminder program would yield the biggest "bang for the buck." The observation that the threat of sanctions is especially effective in reducing FTA in the context of misdemeanor level offenses could be used to reduce FTA in other contexts, such as reducing the number of citizens who do not respond to their jury summons (Seltzer, 1999), or decreasing failure to pay child support.

The findings can also help in developing programs that better estimate the impact that various court interventions will have on reducing FTA. The literature on pretrial service programs' ability to reduce FTA and to ensure community safety is relatively small. In addition to the utility for practitioners in the implementation of programs, being able to quantify the impact of pretrial service program interventions also improves the predictive power of pretrial risk assessment instruments, such as those that calculate latent risk (Bhati, 2010).

In the present study, defendants who appeared for court had greater trust in the courts and perceived that they were treated with greater fairness and respect from the time of their ticket to the time they completed the survey, compared to nonappearers. Trust and confidence in legal institutions, which is closely related to, yet arguably distinct from, procedural justice (Rottman, 2007; Tyler, 2006a, 2006b), has been identified by both researchers (e.g., Benesh, 2006; Rottman et al., 2003; Ty- 
ler, 2006b) and members of the judiciary (e.g., O'Connor, 1999) as important. Efforts to increase trust and confidence-especially in populations likely to offend could potentially yield lower FTA rates (the observed correlation between trust/ confidence and appearance does not, of course, necessarily imply a causal relationship).

Outreach efforts by the courts are one way to accomplish this goal (National Center for State Courts, 2005). Indeed, when it comes to reducing the overrepresentation of minorities in the criminal justice system, community-based outreach efforts-such as investing resources in local institutions and social services-are likely to be more effective than "law-and-order" measures at increasing trust in the courts and other governmental institutions among groups, such as African Americans, with relatively low trust (Roberts, 2004; Weitzer \& Tuch, 2006). Increased trust, then, would be associated with greater compliance.

\section{Conclusion}

This study demonstrates that it is possible to reduce the risk of FTA with a postcard reminder system. Substantive reminders - that is, those with information about possible sanctions - were more effective than a simple reminder. FTA rates varied across a number of offender characteristics, such as geographic location (rural vs. urban), offense type, and number of charges. FTA was highest for Blacks, but this difference was not statistically significant when controlling for these other factors. Reminders were somewhat less effective for Blacks than for Whites and Hispanics.

Misdemeanor defendants who appeared in court had more confidence in the courts and a greater sense of procedural justice than defendants who did not appear. There was evidence that the reminder manipulation's effectiveness varied as a function of defendants' level of trust and confidence, suggesting that raising trust and confidence could be reasonably expected to reduce FTA. Overall, the present study shows promise that there are ways of ameliorating the costly problem of FTA.

\section{References}

Arapahoe County Justice Center. (2010). Court date notification. Retrieved from http://www .co. arapahoe.co.us/Departments/CS/JudicialServices/Court\%20Date\%20Notification \%20Program. asp.

Barry, H., \& Tyler, T. R. (2009). The other side of injustice: when unfair procedures increase groupserving behavior. Psychological Science 20: 1,026-1,032. DOI: 10.1111/j.1467-9280.2009.02404.x.

Baum, L. (2006). The Supreme Court (9th Ed.). Washington, D.C.: CQ Press.

Benesh, S. C. (2006). Understanding public confidence in the American courts. Journal of Politics 68: 697-707. DOI: 10.1111/j.1468-2508.2006.00455.x.

Bhati, A. (2010). Reassessing Risk Assessment: Measuring Latent Risk in Pretrial Populations to Predict Crime. Working paper. Gaithersburg, Md.: Maxarth.

Blumenthal, J. A. (2002). Law and social science in the twenty-first century. Southern California Interdisciplinary Law Journal 12: 1-53. 
Bornstein, B. H., \& Dietrich, H. (2007). Fair procedures, yes. But don't forget fair outcomes. Court Review 44: 72-77.

Brooks, R. R. W., \& Jeon-Slaughter, H. (2001). Race, income and perceptions of the U.S. court system. Behavioral Sciences \& the Law 19: 249-264. DOI: 10.1002/bsl.442.

Caldeira, G. A. (1986). Neither the purse nor the sword: Dynamics of public confidence in the Supreme Court. American Political Science Review 80: 1,209-1,226. DOI: 10.2307/1960864.

Circuit Court of Cook County. (2006). Summary of Juvenile Probation and Court Services Programs and Initiatives 2006. Cook County, Ill.: Author. Retrieved from http://www.cookcountycourt.org/ publications/pdf/juvenile_book.pdf.

Corbie-Smith, G., Thomas, S. B., \& St. George, M. M. (2002). Distrust, race, and research. Archives of Internal Medicine 162: 1,458-2,463. DOI: 10.1001/archinte.162.21.2458.

Covington, J. (1995). Racial classification in criminology: the reproduction of racialized crime. Sociological Forum 10: 547-568. DOI: 10.1007/BF02095768.

Crozier, T. L. (2000). The Court Hearing Reminder Project: If You Call Them, They Will Come. Institute for Court Management, Court Executive Development Program.

Curry, J. M. (2000). Community worldview and rural systems: a study of five communities in Iowa. Annals of the Association of American Geographers 90: 693-712. DOI: 10.1111/0004-5608.00218.

Cuvelier, S. J., \& Potts, D. W. (1997). A Reassessment of the Bail Classification Instrument and Pretrial Practices in Harris County, TX. Huntsville, Tex.: Sam Houston State University.

Davis, W. (2005). Should Georgia change its misdemeanor arrest laws to authorize issuing more field citations? Georgia State University Law Review 22: 313-359.

deHooge, I. E., Breugelmans, S. M., \& Zeelenberg, M. (2008). Not so ugly after all: when shame acts as a commitment device. Journal of Personality and Social Psychology 95: 933-943. DOI: 10.1037/ a0011991.

Dillman, D. A. (2007). Mail and Internet Surveys: The Tailored Design Method. Hoboken, N.J.: Wiley.

Gerber, A. S., Green, D. P., \& Larimer, C. W. (2010). An experiment testing the relative effectiveness of encouraging voter participation by inducing feelings of pride or shame. Political Behavior 32: 409422. DOI: $10.1007 /$ s11109-010-9110-4.

Gibson, J. L., Caldeira, G. A., \& Spence, L. K. (2003). Measuring attitudes toward the United States Supreme Court. American Journal of Political Science 47: 354-367. DOI: 10.1111/1540-5907.00025.

Gibson, J. L., Caldeira, G. A., \& Spence, L. K. (2005). Why do people accept public policies they oppose? Testing legitimacy theory with a survey-based experiment. Political Research Quarterly 58: 187-201. DOI: $10.1177 / 106591290505800201$.

Goldkamp, J. S., \& White, M. D. (2006). Restoring accountability in pretrial release: the Philadelphia pretrial release supervision experiments. Journal of Experimental Criminology 2: 143-181. DOI: 10.1007/s11292-006-9001-1.

Hamm, J. A., PytlikZillig, L. M., Tomkins, A. J., Herian, M. N., Bornstein, B. H., \& Neeley, E. M. (2011). Exploring separable components of institutional confidence. Behavioral Sciences \& the Law 29: 95-115. DOI: 10.1002/bsl.965.

Hegtvedt, K. A., Johnson, C., Ganem, N. M., Waldron, K. W., \& Brody, L. M. (2009). When will the unaffected seek justice for others? Perceptions of and responses to another's injustice. Australian Journal of Psychology 61: 22-31. DOI: 10.1080/00049530802607613.

Helland, E., \& Tabarrok, A. (2004). The fugitive: Evidence on public versus private law enforcement from bail jumping. Journal of Law and Economics 43: 97-122. DOI: 10.1086/378694.

Hitlin, S., Brown, J. S., \& Elder, Jr., G. H. (2007). Measuring Latinos: Racial vs. ethnic classifications and self-understandings. Social Forces 86: 587-611.

Jefferson County Criminal Justice Planning. (2005). Jefferson County, CO court date notification program FTA pilot project summary, 2005-11-09. Jefferson County, Colo.: Author. Retrieved from http://www.co.jefferson.co.us/jeffco/cjp_uploads/FTA_Pilot_Project_Summary.pdf.

Kandel, W., \& Cromartie, J. (2004). New patterns of Hispanic settlement in rural America. Rural Development Research Report No. (RDRR-99). Retrieved from http://www.ers.usda.gov/Publications/RDRR99/. 
Larson, E. B., Bergman, J. Heidrich, F., Alvin, B. L., \& Schneeweiss, R. (1982). Do postcard reminders improve influenza vaccination compliance? A prospective trial of different postcard cues. Medical Care 20: 639-648. DOI: 10.1097/00005650-198206000-00010.

Levin, J. K., Kennel, J. R., Pellegrino, C., Simmons, K., \& Surette, E. (2007). Bail, release and detention pending proceedings. In Corpus Juris Secundum (Vol. 8, §§ 125, 127). St. Paul, Minn.: West.

Lind, E. A., \& Tyler, T. R. (1988). The Social Psychology of Procedural Justice. New York: Plenum Press.

MacCoun, R. J. (2005). Voice, control, and belonging: The double-edged sword of procedural justice. Annual Review of Law and Social Science 1: 171-201. DOI: 10.1146/annurev.lawsocsci.1.041604.115958.

McAdams, R. H. (2000). A focal point theory of expressive law. Virginia Law Review 86: 1,649-1,729. DOI: $10.2139 /$ ssrn.254420.

McGinty, T. J. (2000). Straight release: Justice delayed, justice denied. Cleveland State Law Review 48: 235-309.

Murphy, K., \& Tyler, T. (2008). Procedural justice and compliance behavior: The mediating role of emotions. European Journal of Social Psychology 38: 652-668. DOI: 10.1002/ejsp.502.

Murphy, K. (2008). Procedural justice and affect intensity: understanding reactions to regulatory authorities. Social Justice Research 22: 1-30. DOI: 10.1007/s11211-008-0086-8.

National Center for State Courts. (1999). How the Public Views the State Courts: A 1999 National Survey. Williamsburg, Va.: Author. Retrieved from http://digitalcommons.unl.edu/publicpolicypublications/25/

National Center for State Courts. (2005). Trial Court Performance Standards and Measurement System. Williamsburg, Va.: Author. Retrieved from http://www.ncsconline.org/D_Research/tcps/index.html.

O'Connor, S. D. (1999). Public trust as a dimension of equal justice: Some suggestions to increase public trust. Court Review 36: 10-13.

O'Keefe, M. (2007). Court appearance notification system: 2007 analysis highlights. Local Public Safety Coordinating Council. Retrieved from http://www2.co.multnomah.or.us/County_Management/Budget/Budget \%20Office \% 20Evaluation/Reports/Public\%20Safety\%20Research/ CANS\%20Highlights.pdf.

Roberts, D. E. (2004). The social and moral cost of mass incarceration in African American communities. Stanford Law Review 56: 1,271-1,305.

Robinson, P. H., \& Darley, J. M. (1997). The utility of desert. Northwestern University Law Review 91: 453-499. DOI: 10.2139/ssrn.10195.

Rosenbaum, D. I., Hutsell, N., Tomkins, A. J., Bornstein, B. H., Herian, M. N., \& Neeley, E. M. (in press). Using court date reminder postcards to reduce courts' failure to appear rates: a benefit-cost analysis. Judicature.

Rottman, D. (2007). Adhere to procedural fairness in the justice system. Criminology and Public Policy 6: 835-842. DOI: 10.1111/j.1745-9133.2007.00478.x.

Rottman, D. B., Hansen, R., Mott, N., \& Grimes, L. (2003). Perceptions of the Courts in Your Community: The Influence of Experience, Race and Ethnicity. Williamsburg, Va.: National Center for State Courts. Retrieved from http://www.ncjrs.gov/pdffiles1/nij/grants/201356.pdf.

Rottman, D. B., \& Tomkins, A. J. (1999). Public trust and confidence in the courts: What public opinion surveys mean to judges. Court Review: The Journal of the American Judges Association 36: 24-31. DOI: $10.1002 /$ bsl.441.

Scholz, J. T., \& Lubell, M. (1998). Trust and taxpaying: testing the heuristic approach to collective action. American Journal of Political Science 42: 398-417. DOI: 10.2307/2991764.

Seltzer, R. (1999). The vanishing juror: why are there not enough available jurors. Justice System Journal 20: 203-218.

Skitka, L. J., Winquist, J., \& Hutchinson, S. (2003). Are outcome fairness and outcome favorability distinguishable psychological constructs? A meta-analytic review. Social Justice Research 16: 309-341.

The Court Brothers (2010a). FTA Repository. Retrieved from http://www.thecourtbrothers.com/ web_court/fta_fta_repository.pl.

The Court Brothers (2010b). Reminder Call Service. Retrieved from http://www.thecourtbrothers. com/web_court. 
Thibaut, J., \& Walker, L. (1975). Procedural Justice. Hillsdale, N.J.: Erlbaum.

Tomkins, A. J., \& Applequist, K. (2008). Constructs of justice: beyond civil litigation. In: B. H. Bornstein, R. L. Wiener, R. Schopp, \& S. L. Willborn (Eds.), Civil Juries and Civil Justice: Psychological Perspectives (pp. 257-272). New York, N.Y.: Springer.

Tyler, T. R., \& Rasinski, K. (1991). Procedural justice, institutional legitimacy, and the acceptance of unpopular U.S. Supreme Court decisions: a reply to Gibson. Law and Society Review 25: 621-630. DOI: $10.2307 / 3053729$.

Tyler, T. R. (2001). Public trust and confidence in legal authorities: What do majority and minority group members want from the law and legal authorities? Behavioral Science and the Law 19: 215-235. DOI: $10.1002 /$ bsl.438.

Tyler, T. R. (2006a). Psychological perspectives on legitimacy and legitimation. Annual Review of Psychology 57: 375-400. DOI: 10.1146/annurev.psych.57.102904.190038.

Tyler, T. R. (2006b). Why People Obey the Law. Princeton, N.J.: Princeton University Press. (Original work published 1990)

Tyler, T. R. (2007). Does the American public accept the rule of law? The findings of psychological research on deference to authority. DePaul Law Review, 56: 661.

VanNostrand, M., \& Keebler, G. (2009). Pretrial Risk Assessment in the Federal Court. Washington, D.C.: Office of the Federal Detention Trustee, U.S. Department of Justice.

Vroom, V. H. (1964). Work and Motivation. New York: Wiley.

Weitzer, R., \& Tuch, S. A. (2006). Race and Policing in America: Conflict and Reform. New York: Cambridge University Press.

White, W. (2006, May). Court hearing call notification project. Unpublished report, Criminal Justice Coordinating Council \& Flagstaff Justice Court, Coconino County Arizona. Retrieved from www. coconino.az.gov/uploadedFiles/Criminal_Justice_Coordinating_Council/ReportFTA.doc.

Wiener, R. L. (2007). Law and everyday decision making: rational, descriptive, and normative models. In: R. L. Wiener, B. H. Bornstein, R. F. Schopp, \& S. L. Willborn (Eds.), Social Consciousness in Legal Decision Making: Psychological Perspectives (pp. 3-32). New York: Springer.

Article history: Received May 23, 2011; revision received September 26, 2011; accepted October 5, 2011. 